\title{
Correction to: Boosting robot-assisted rehabilitation of stroke hemiparesis by individualized selection of upper limb movements - a pilot study
}

Orna Rosenthal ${ }^{1 *}$, Alan M. Wing ${ }^{1}$, Jeremy L. Wyatt ${ }^{2}$, David Punt ${ }^{3}$, Briony Brownless ${ }^{1}$, Chit Ko-Ko ${ }^{4}$ and R. Christopher Miall ${ }^{1}$

\section{Correction: J Neuroeng Rehabil} https://doi.org/10.1186/s12984-019-0513-0

The original article [1] contained a minor error in the following sentence in the Discussion:

... a baseline level of at least 31 points would be needed to benefit from control training.'

The aforementioned sentence has now been corrected to state the following:

¿.. a baseline level of at least 42 points would be needed to benefit from control training.'

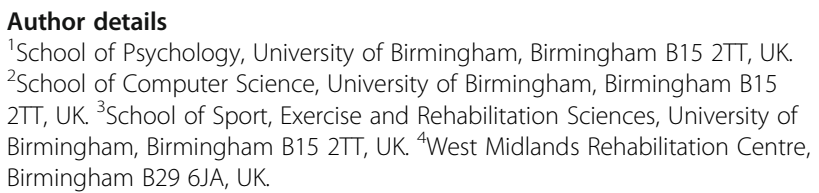

\section{Reference}

1. Rosenthal O, et al. Boosting robot-assisted rehabilitation of stroke

hemiparesis by individualized selection of upper limb movements - a pilot

study. Journal of NeuroEngineering and Rehabilitation. 2019;16:42 https://

doi.org/10.1186/s12984-019-0513-0.

\footnotetext{
* Correspondence: o.rosenthal.bham@gmail.com

'School of Psychology, University of Birmingham, Birmingham B15 2TT, UK

Full list of author information is available at the end of the article
} 